\title{
PHENOTYPIC AND MOLECULAR IDENTIFICATION OF YEASTS ISOLATED FROM CULTURED TILAPIA (OREOCHROMIS NILOTICUS) IN KAFRELSHEIKH PROVINCE, EGYPT
}

\author{
Amgad A. Moawad ${ }^{1 *}$, Ahmed I. Noor El Deen², Nadia B. Mahfouz ${ }^{3}$, Salwa M. Helmy ${ }^{1}$, \\ Yasmen F. Hashem ${ }^{4}$
}

${ }^{1}$ Departments of Bacteriology, Mycology \& Immunology Department, Faculty of Veterinary Medicine, Kafrelsheikh University, Egypt, ${ }^{2}$ Department of Hydrobiology, Veterinary Division, National Research Center, Egypt, ${ }^{3}$ Department of Fish Diseases and Management, Faculty of Veterinary Medicine, Kafrelsheikh University, Egypt, ${ }^{4}$ Veternarian in Directorate of Veterinary Medicine in Kafrelsheikh, Egypt

*Corresponding author, E-mail: Moawadamgad@gmail.com

\begin{abstract}
The present study aimed to identify yeasts by phenotypic, biochemical and genotypic methods. Three hundred live Oreochromis niloticus samples were collected from different locations at Kafrelsheikh Governorate, Egypt and during different seasons. Yeast isolates were identified according to their phenotypical characterization in combination with polymerase chain reaction (PCR) and restriction fragment length polymorphism (RFLP) method. Two hundred and twenty-six yeast isolates from eighty diseased and two hundred and twenty apparently healthy $O$. niloticus samples. Isolated yeasts were Rhodotorula spp. (18.14\%), Candida albicans (19.47\%), Candida parapsilosis (16.37\%), Candida guilliermondii (14.6\%), Candida inconspicua (8.85\%), Trichosporon asahii (17.25\%), Geotrichum spp. (2.66\%) and unidentified Ascus forming yeasts $(2.66 \%)$. Yeasts most frequently isolated from gills and skin. Phenotypic methods are valuable in identification of yeasts into genera but these methods take more time. Molecular methods through the amplification of (internal transcribed spacer) ITS1-5.8S-ITS2 regions of fungal rRNA, followed by RFLP-PCR using Msp1 restriction enzyme allowed simple, rapid, cost-effective, sensetive and accurate identification of the phenotypically identified yeasts.
\end{abstract}

Key words: Oreochromis niloticus; yeast; PCR; Msp1; PCR-RFLP

\section{Introduction}

Parasitic fungi are facultative saprophytic (1). Yeasts are identified according to the ability of sugars fermentation and assimilation of carbon and nitrogen compounds (2). Fungal reproduction is not simple and depends upon more than one method of propagation. Environmental conditions stimulate formation of special structures that can help in sexual and asexual reproduction by efficiently dispersing spores or spore-containing propagates (3). Unicellular reproduction can occur by budding, fission or by both processes, called bud fission. Yeasts that reproduce sexually are members of 
two large phyla of the fungi and have different modes of sporulation. After meiosis ascomycetous yeasts produce different shapes of ascospores inside an ascus that is not enclosed in a complex fruiting body or an ascocarp. Basidiomycetous yeasts show a wide variety in the basidium morphology, where the formation of the external meiotic spores (4). Phylogenetic and population genetic methods are used to identify species and pathogenic fungi and detect the modality of their reproduction in nature (5). Fish that infected by fungi was previously exposed to some other pathogens or stressors like bacterial, viral, parasitic diseases, poor water quality and trauma (6). Fungal can infect externally or internally and over the past decade fungi have received high attention all over the world (7). Many of fungi are considered opportunists because attacking fish under the effect of different stressors (8).

Conventional identification of pathogenic yeasts depends on the morphological and biochemical characters using tests that need more time. Also, the available commercial methods frequently fail to identify the less common pathogens or to differentiate between closely related species. Molecular methods used for the identification are rapid and sensitive alternatives to conventional identification for yeasts (9). RFLP method was relatively more accurate and reliable for the detection of various yeasts compared PCR (10).

The present study was conducted to isolate and identify yeast from freshwater fish by phenotypic methods and study reproductive behavior on different culture media, rice agar for asexual spores while carrot media for detection of sexual spores. Molecular identification of yeast by RFLP-PCR was further applied to confirm phenotypic results.

\section{Materials and methods}

A total of 300 live $O$. niloticus comprised 80 clinically diseased and 220 apparently healthy fish were collected from private fish farms at Kafrelsheikh province. The Body weights were ranged from $150 \pm 10 \mathrm{~g}$. The collected fish were examined clinically with paying attention to the behaviors in the ponds, changes in color and respiratory manifestations with special care to the external lesions according to the methods described by (11). The samples were collected aseptically transferred alive to the provisional laboratory of department of microbiology in faculty of veterinary medicine, Kafrelsheikh University.

The live fish samples were transferred in a separate plastic bags one-third volume of water and provided with oxygen aeration by battery aerator (Beauty, Italy) and then subjected to mycological examination.

\section{Media}

Sabouraud's dextrose agar (SDA) (oxoid). It was used for isolation and preservation of fungi according to (13), Germ tube test (14) for detection of reproductive behavior, Rice agar media (15) for asexual reproduction of yeasts, Carrot agar (CA) (16) for induction of sexual sporulation of fungi, differential and selective chromogenic medium for the isolation and quick identification of Candida spp., Christensen's urea agar (Oxoid) for biochemical identification,

\section{Isolation of yeast}

The obtained samples were inoculated into duplicate plates of SDA with $500 \mathrm{mg}$ of chloramphenicol dissolved in $3 \mathrm{ml}$ ethanol $95 \%$ (that were added to the media after autoclaving). The inoculated plates were incubated at $30^{\circ} \mathrm{C}-37^{\circ} \mathrm{C}$. A pure culture of each yeast colony was collected and the genus identified based on morphological characteristics (13).

\section{RFLP-PCR}

RFLP-PCR was carried out using primers (to amplify the ITS-1 and ITS-2 regions of yeast spp. using universal primers (internal transcribed spacer) ITS1 (5'-TCC GT AGGTGAACCTGCCGG-3') and ITS4 (5'-TC CTCCGCTTATTCATATGC-3') and Mspl restriction enzyme for yeast spp. as previously described (17). Before RFLP-PCR, DNA extraction from yeast isolates was performed using DNA isolation kit (Jena Bioscience) and as previously described (18). 


\section{Results}

\section{Phenotypic identification of yeast isolates}

Yeast isolates were identified according to microbiological characters (hyphae, pseudohyphae, chlamydospores, and blastospores) into genera. Two hundred and twenty-six yeast isolates that yielded from the samples were identified into 4 genera (Candida, Rhodotorula, Trichosporon and Geotrichum).

\section{Identification of Candida species}

One hundred and thirty-four isolates of Candida spp. were subjected for identification according to the following (Fig. 1):

A. Macromorphology on SDA

C. albicans colonies were characterized by creamy colored pasty colonies within 48-72hrs, germ tube positive, grew well on media containing cycloheximide with light green colonies on chromogenic candida agar, while $C$. parapsillosis colonies were white and smooth colonies on both SDA and chromogenic Candida agar with no growth on media containing cycloheximide. C. guilliermondii colonies were dull, white, creamy or yellow, flat smooth colonies, while on chromogenic agar, they appeared pale pink to purple. Other Candida spp had the same cultural characters on SDA but can't grow on media containing cycloheximide; with light pink colonies on Chromogenic candida agar and showed negative germ tube test.

B. Micromorphology on Rice agar media

Isolates could be identified into $C$. albicans according to Rice agar media which showed terminal chlamydospores, blastocondia and pseudohyphae. Pseudohyphae of $C$. parapsillosis were long and branched and carried clusters of elongated blastospores without chlamydospores. Other Candida spp. failed to produce pseudohyphae. C. guilliermondii appeared as short branched pseudohyphae bearing clusters of blastospores All Candida isolates were urease negative.

\section{Identification of Trichosporon species}

Thirty-nine isolates of Trichosporon isolated on SDA appeared firstly as smooth flat or wrinkled white to creamy colonies that turned waxy with central folds surrounded by wrinkled furrows. They grew well at $30^{\circ} \mathrm{C}, 37^{\circ} \mathrm{C}$, and also on media containing cycloheximide. Microscopically, hyaline mycelium separated and fragmented into rectangular arthrospores appeared. On Rice agar media, Trichosporon appeared as septated hyphae, pseudohyphae, and arthrospores. Trichosporon species were urease positive.

\section{Identification of Rhodotorula species}

Forty-one isolates Rhodotorula were identified on SDA as Rhodotorula spp. (light pink flat colonies). It grows well at $30^{\circ} \mathrm{C}$ with faint growth at $37^{\circ} \mathrm{C}$, no growth on media containing cycloheximide. Microscopic examination of Gram's stained films revealed large round yeast cells, on Rice agar media showed large round blastoconidia with no pseudohyphae. Rhodotorula spp. was urease positive.

\section{Identification of Geotrichum species}

Six isolates Geotrichum spp. were identified on SDA as they grew rapidly as white to creamy, flat and smooth, yeast-like colonies which turned into mold-like in old colonies, grew at $30^{\circ} \mathrm{C}$ but not at $37^{\circ} \mathrm{C}$, or on media containing cycloheximide. Micromorphology, hyaline septated branched hyphae break up into short chains or individual arthroconidia appeared. No pseudohyphae or blastoconidia were formed, a character which differentiated it from Trichosporon species. Arthroconidia produced a hyphal extension from one corner producing a hockey stick appearance. Geotrichum spp. was urease negative.

\section{Phenotypic identification of yeast isolates}

Molecular identification of yeast isolates

Results obtained by preliminary conventional identification of yeast isolates combined with detection of characteristic asexual spore helping in identification of most of them into genera (Candida, Trichosporon, Rhodotorulla, Geotrichum), while using RFLP-PCR we found (C. albicans, C. parapsilosis, C. guilliermondii, C. inconspicua, Trichosporon asahii) (Figs. 2 and 3). Based on the results of RFLP-PCR we determined the incidence of yeast isolates. 
The incidence of yeast spp. isolated from diseased and apparently healthy $O$. niloticus spp. isolated from different organs of $O$. nilotfishes was shown in Table 1. Incidence of yeast icus fishes was shown in Table 2.
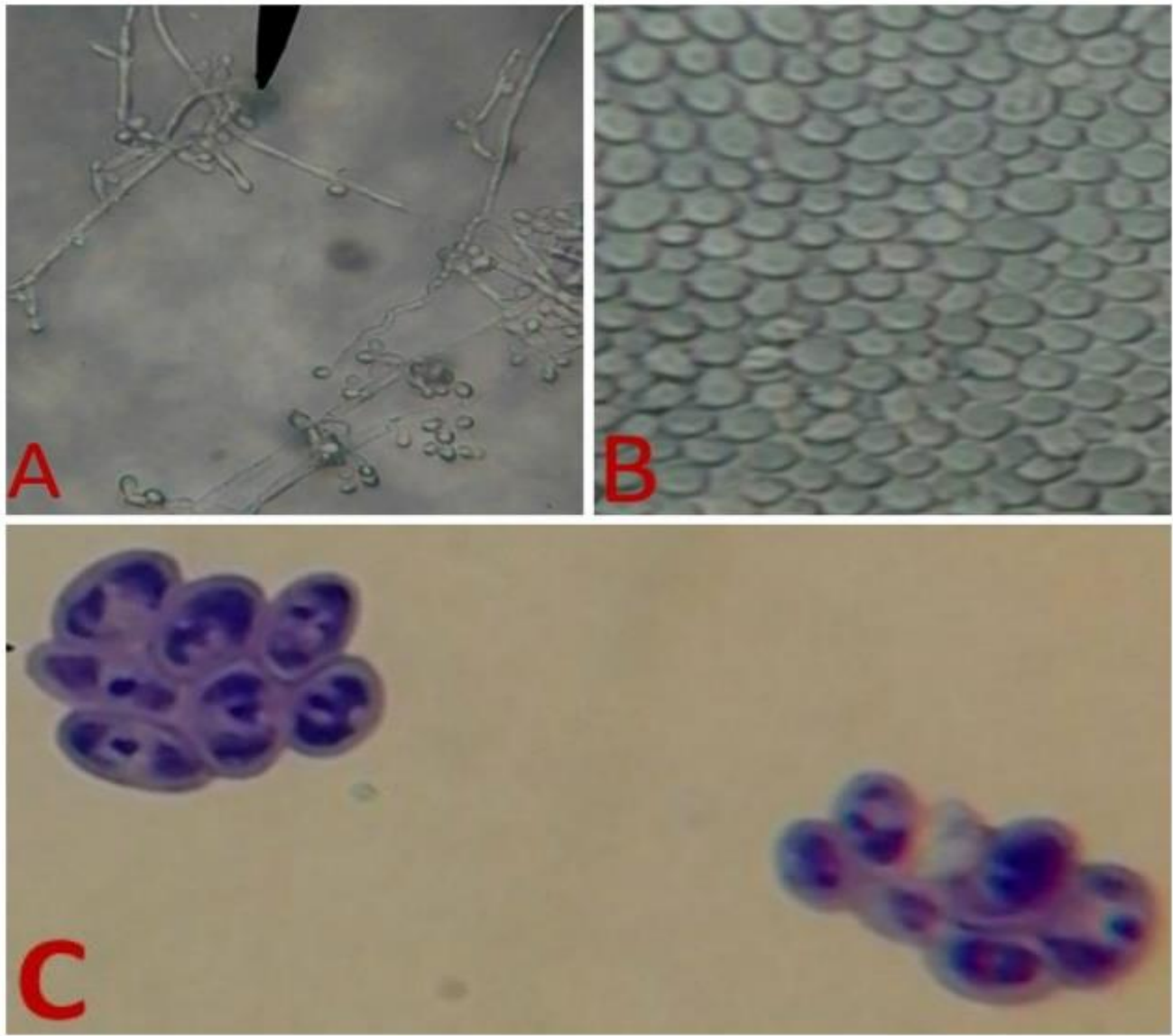

Figure 1: Microscopical identification of isolated yeasts. (A) Candida albicans showed on RAT blastspores, pseudohyphase and chlamydoconidia. (B) Yeast showed on RAT budding cells (blastspores without peudohyphae). (C) Ascospore forming yeast on carrot agar

Table 1: Incidence of yeast spp. isolated from diseased and apparently healthy $O$. niloticus fishes

\begin{tabular}{lcccc}
\hline Isolated yeast & \multicolumn{4}{c}{ No. of examined O. niloticus } \\
& \multicolumn{1}{c}{ No. of diseased (80) } & No. of apparently healthy (220) \\
\hline \multirow{2}{*}{ Rhodotorulla spp. } & No. & $\%$ & No. & $\%$ \\
Candida albicans & 15 & $18.75 \%$ & 30 & $13.63 \%$ \\
Candida parapsilosis & 16 & $20 \%$ & 22 & $7.27 \%$ \\
Candida spp. & 5 & $6.25 \%$ & 15 & $6.81 \%$ \\
Candida guilliermondii & 4 & $5 \%$ & 11 & $5 \%$ \\
Trichosporon spp. & 9 & $11.25 \%$ & 15 & $6.81 \%$ \\
Ascus forming yeast & 6 & $7.5 \%$ & 18 & $8.18 \%$ \\
& 3 & $3.75 \%$ & 7 & $3.18 \%$ \\
\hline
\end{tabular}


Table 2: Incidence of yeast spp. Isolated from different organs of $O$. niloticus fishes

\begin{tabular}{|c|c|c|c|c|c|c|c|c|c|c|}
\hline \multirow[t]{2}{*}{$\begin{array}{l}\text { Isolated } \\
\text { Yeast }\end{array}$} & \multirow[t]{2}{*}{$\begin{array}{l}\text { No. of iso- } \\
\text { lates }\end{array}$} & \multirow[t]{2}{*}{$\%$} & \multicolumn{4}{|l|}{ Organs } & \multicolumn{2}{|l|}{ Liver } & \multicolumn{2}{|c|}{ Kidney } \\
\hline & & & No. & $\%$ & No & $\%$ & No. & $\%$ & No & $\%$ \\
\hline Rhodotorulla spp. & 41 & 18.14 & 12 & 29.3 & 22 & 53.7 & 2 & 4.9 & 5 & 12.2 \\
\hline C. albicans & 44 & 19.47 & 13 & 29.5 & 15 & 34.1 & 10 & 22.7 & 6 & 13.6 \\
\hline C. parapsilosis & 37 & 16.37 & 8 & 21.6 & 19 & 51.4 & 6 & 16.2 & 4 & 10.8 \\
\hline Candida spp. & 20 & 8.85 & 4 & 20 & 10 & 50 & 4 & 20 & 2 & 10 \\
\hline Trichosporon spp. & 39 & 17.25 & 21 & 53.8 & 9 & 23.1 & 9 & 23.1 & 0 & 0 \\
\hline Candida guilliermondii & 33 & 14.6 & 0 & 0 & 18 & 54.5 & 15 & 45.5 & 0 & 0 \\
\hline Geotrichum spp. & 6 & 2.66 & 2 & 33.3 & 3 & 50 & 1 & 16.7 & 0 & 0 \\
\hline $\begin{array}{l}\text { Unidentified Ascus form- } \\
\text { ing yeasts }\end{array}$ & 6 & 2.66 & 2 & 33.3 & 3 & 50 & 1 & 16.7 & 0 & 0 \\
\hline Total & 226 & 100 & 62 & & 99 & & 48 & & 17 & \\
\hline
\end{tabular}

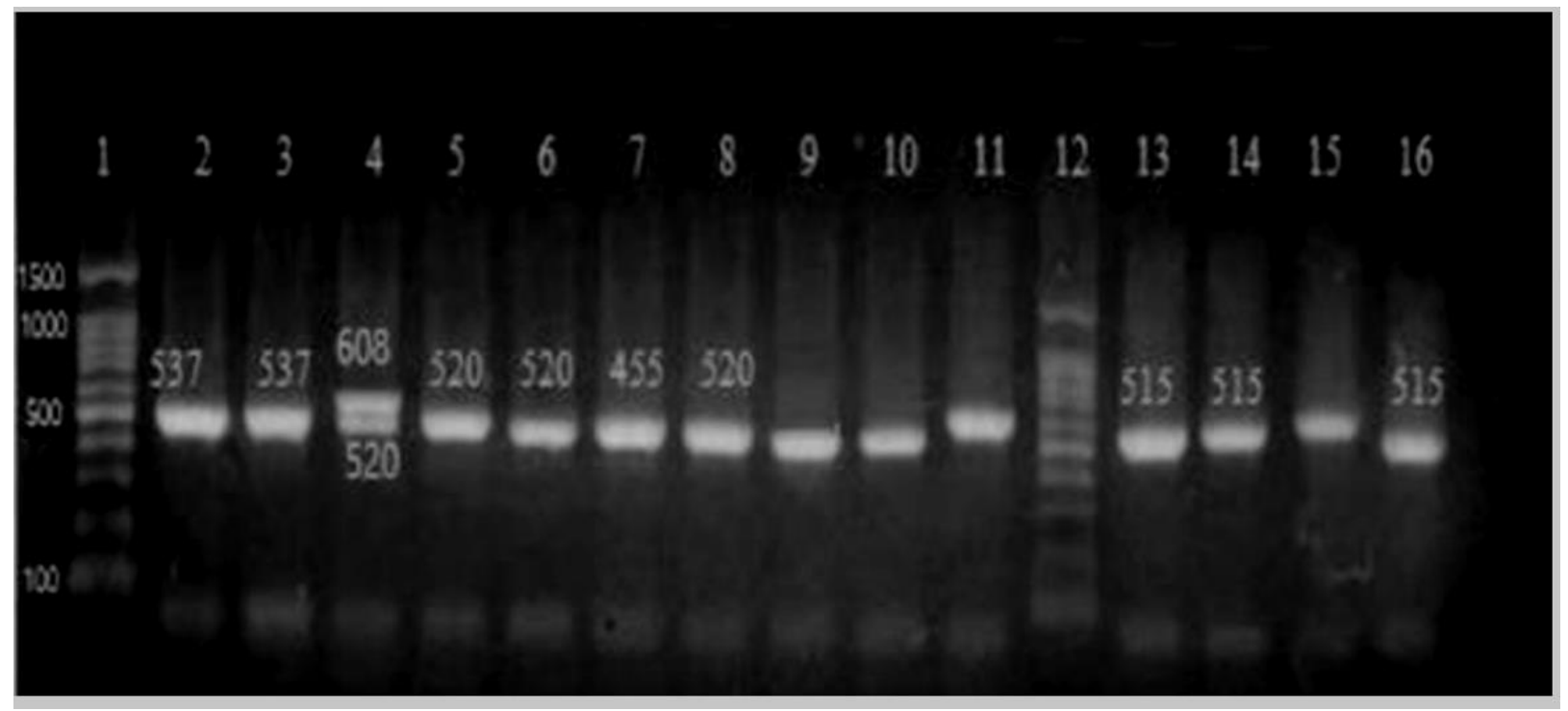

Figure 2: PCR product of yeast isolates, lane 1,12 - 100 bp ladder, lane2-C. albicans, lane3 - C. albicans, lane4 - C. guilliermondii 608bp and C. parapsilosis 520bp, lane5 - C. parapsilosis lane 6 - C. parapsilosis, lane 7 - C. inconspicua, lane 8 -C. parapsilosis lane 9 - Unidentified Candida spp. lane 10 - Unidentified Candida spp. lane 11 Unidentified Candida spp. ,Lane13 - Tr. asahii lane14 - Tr. asahii, lane15 -Unidentified Trichosporon spp. lane16 - Tr. asahii 


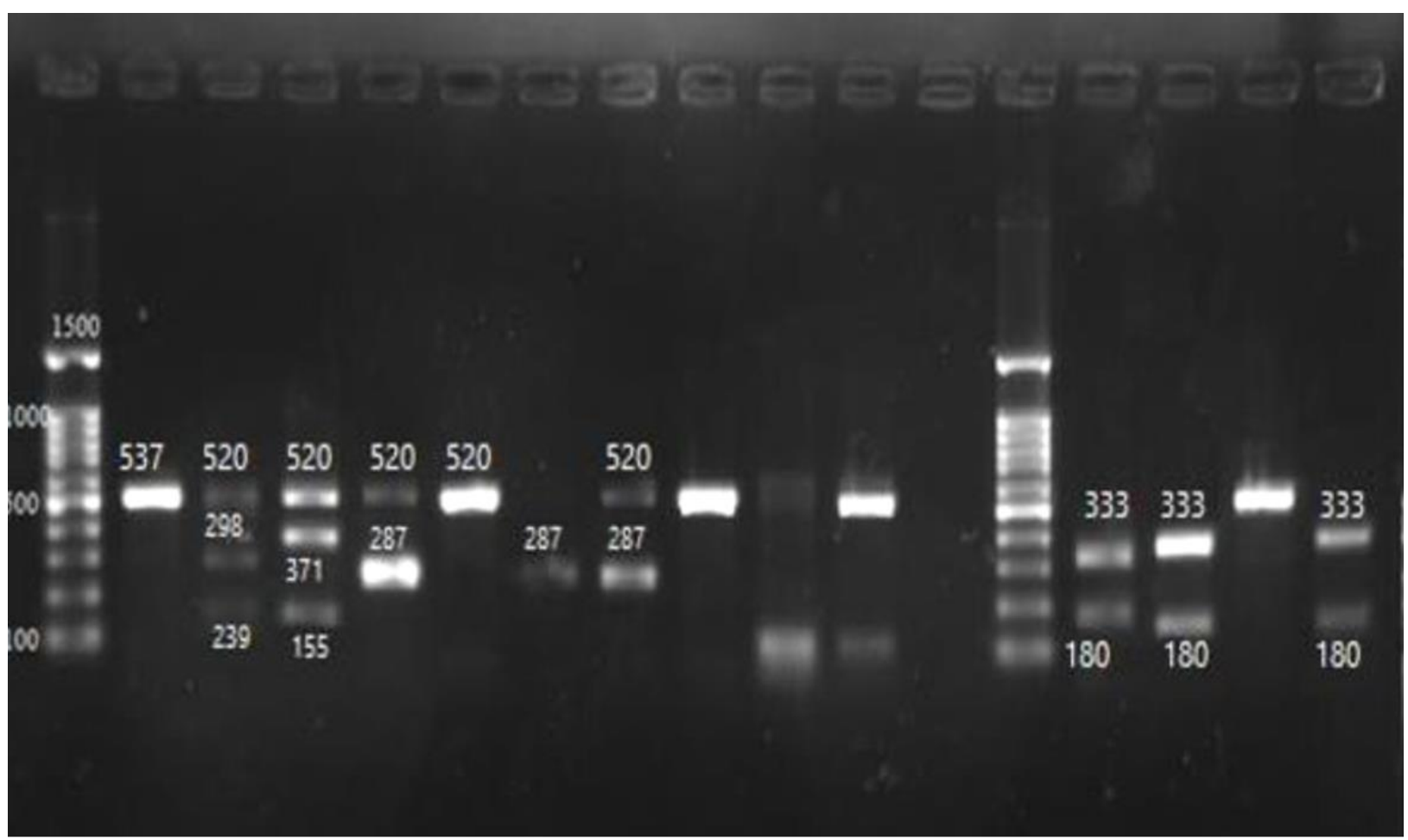

Figure 2: RFLP-PCR of yeast isolates by MSP1 enzyme, lane 1,12 - $100 \mathrm{bp}$ ladder, lane2- C. albicans, lane3 - C. albicans and C. parapsilosis, , lane4 - C.parapsillosis and C. guillerimondi, lane5 - C. parapsillosis and C. inconspicua lane 6 - C. parapsilosis, lane 7 - C. inconspicua, lane 8 - C. C. parapsillosis and C. inconspicua lane 9 - Unidentified Candida spp., lane 10 - Unidentified Candida spp, lane 11Unidentified Candida spp. Lane13 - Tr. asahii lane14 -Tr. asahii, lane15 - Unidentified Trichosporon spp., lane16 - Tr. Asahi

\section{Discussion}

Yeasts play a key role in several ecosystem processes, establishing ecological relations with other organisms which have been identified as a part of wild caught as well as farmraised fish microbiota and display an ability to interfere with the fish's nutrition and sanitary conditions (19). 226 yeast isolates out of 300 $(75.33 \%)$ were isolated, with 5 genera: Candida, Rhodotorula, Trichosporon, Geotrichum and unidentified ascus forming yeast from $O$. niloticus. Candida spp. and were isolated at an incidence of $59.29 \%(134 / 226)$ and $18.14 \%$ (41/226), respectively. These results agreed with those recorded by (20) who isolated Candida spp. and Rhodotorula spp. at incidence rate of $65.12 \%$ and $28.84 \%$, respectively.

C. albicans (19.47\%) and Rhodotorula spp. $(18.14 \%)$ were the highest yeast isolates collected from skin, gills, kidney, and liver and.
These results coincided with (21) who found incidence of $C$. albicans, and Rhodotorula spp. at $35.9 \%$ and $31.4 \%$, respectively.

Trichosporon spp. was isolated with higher incidence $(17.25 \%)$ and lower rate for Geotrichum spp. (2.66\%) and ascus forming unidentified yeast $(2.66 \%)$. Nearly similar results were recorded by (22). But (20) recorded that Trichosporon spp. (4.18\%), and also Geotrichum spp. and ascus forming unidentified yeast in a low percent $0.46 \%$. C. guilliermondii and $C$. parapsilosis were isolated in higher number that in agreement with (23) who found a rising of these pathogens but in freshwater environment.

In the present study, several species of genus Candida (such as C. parasitosis, C. guilliermondii and $C$. inconspicua) were mostly isolated from gills nearly by $50 \%$. There is an evidence that exposure to environmental stressors can predispose fish to infection according to 
(24). The polluted feeds, water and worker hands play important role in fish health (25). We observed that many yeast species that affect human have been isolated from freshwater environments. Terrestrial environments and wastewater may be the origin of many of these species (26).

Molecular approaches exhibit the potential to be a strong supplement for the phenotypic identification than the conventional methods (27). The most frequently used targets for yeast identification is the ITS region, which lies between the $18 \mathrm{~S}$ and $28 \mathrm{~S}$ rRNA gene and divided by $5.8 \mathrm{~S}$ rRNA gene into ITS1 and ITS2 regions. In many studies the ITS2 showed considerable interspecies variability to identify $99.7 \%$ of yeasts and $100 \%$ of molds to species level, while ITS1 had identification accuracy of $96.8 \%-100 \%$ for yeasts and $100 \%$ for molds (28). Although ITS2 has been used in wide range for identification of fungi, in other study the ITS1 exhibit higher interspecies variability than ITS2 region (29). PCR-RFLP assays have been used to identify the isolated yeast species as was successfully done by (30). An advantage of this method is the stable and easyto-read RFLP patterns. Unlike previous reports, this method involves only one or two DNA fragments. Also, it is easy and rapid to perform. In addition to time-saving restriction enzymes it takes few hours to be completed. It requires no complicated equipment except a traditional thermal cycler. Regarding that DNA sequencer may not be easily obtainable to most clinical laboratories, this molecular method is applicable for obvious identification and differentiation of different yeast species (31).

In the present study, yeast samples that was molecularlt identified as Candida spp. by universal primers became specifically identified as C. inconspicua by RFLP either in samples mixed with $C$. parapsilosis or alone. All examined isolates showed comparable RFLP patterns to their respective reference strains. Regarding to genus Rhodotorula is commonly observed in fish microbiota, as Trichosporon that in agreement with (32). Also, Trichosporon asahii is the most frequently isolated species in these infections that agreed with this study as
PCR-RFLP assure the present results (33). The remaining unidentified Candida spp or unidentified ascus forming yeasts need for sequencing for accurate defining of yeast species.

\section{Conclusion}

Yeasts isolated from healthy and diseased $O$. niloticus included Candida, Trichosporon, Rhodotorula, Geotrichum. Phenotypic methods succeed in the identification of yeasts into genera. Molecular methods using RELP PCR confirm the phenotypic identification and specifically identify the unknown species. The RFLP method follows a common protocol that can be done for identification of yeasts in few hours. So, it can be used substitutional to the traditional methods.

\section{References}

1. Eli A, Briyai OF, and Abowei JFN. A review of Some Fungi Infection in African Fish Saprolegniasis, Dermal Mycoses; Branchiomyces infections, Systemic Mycoses and Dermocystidium. Asian Journal of Medical Sciences 2013; 3(5): 198 205.

2. Refai MK, Marouf S, Nermeen A, and Rasha HS. Monograph on Fungal Diseases of Fish A guide for postgraduate students 2016; Part 1. pp288.

3. Ali HH. Isolation and Identification of Pathogenic Fungi from Carp fish in Suliamania Province. Global Journal of Bio-science and Biotechnology 2015; 4(4): 356-63.

4. Lachance M. Yeasts. University of Western Ontario, Ontario, Canada. John Wiley \& Sons, Ltd: Chichester 2011. Dol:10. 1002/9780470015902. a0000380. pub2.

5. Mousavi SA, Samira SS, Rezaie S, Nejad NS, Hadizadeh S, Kamyabi H, and Aghasi H. Identification of Candida Species Isolated From Oral Colonization in Iranian HIV-Positive Patients, by PCRRFLP Method. undishapur Journal Microbiology 2012; 5(1): 336-40.

6. Noor El-Deen A, Mohamed HO, Mona SZ, and Hanan AA. Mass Mortality in Cultured Nile Tilapia Oreochromis niloticus due to Saprolegniasis with Emphasis on Treatment Trials. Journal of Biological Sciences. 2018; 18(1): 39-45.

7. Yanong RE, VMD. Fungal disease of fish. The Veterinary Clinics Exotic Animal Practice 2003; (6): 377-400. 
8. Quiniou SMA, Bigler S, and Clem LW. Effects of water temperature on mucous cell distribution in channel catfish epidermis: a factor in winter saprolegniasis. Fish Shellf Immunology 1998; 8:111.

9. Linton CJ, Borman AM, Grace Cheung, Holmes AD, Szekely A, Palmer MD, Bridge PD, Campbell CJ, and Johnson EM. Molecular Identification of Unusual Pathogenic Yeast Isolates by Large Ribosomal Subunit Gene Sequencing. Journal Clinical Microbiology 2007; 45(4): 1152-8.

10. Byung HO, Young CS, Yang WL, Yong BC, and Kyu JA. Comparison of Nested PCR and RFLP for Identification and Classification of Malassezia Yeasts from Healthy Human Skin Annals of Dermatology 2009; 21(4): 352-7.

11. Noga EJ. Text Book of Fish Disease: Diagnosis and treatment. 2nd ed. USA: Wiley-Blackwell 2010; pp: 519.

12. El-Adawy M, El-Aziz M A, El-Shazly K, Ali N G, El-Magd M A. Dietary propionic acid enhances antibacterial and immunomodulatory effects of oxytetracycline on Nile tilapia, Oreochromis niloticus, Environmental Science and Pollution Research. DOI:10.1007/s11356-018-3206-5 2018.

13. Taha M. Medical mycology "Atlas of medically important \& dermatomycosis". 1st ed., Mecca printing house, Cairo, Egypt. 2011.

14. Sheppard DC, Locas M, Christiane Restieri C, Laverdiere M. Utility of the Germ Tube Test for Direct Identification of Candida albicans from Positive Blood Culture Bottles. Journal of Clinical Microbiology 2008; 46(10): 3508-9.

15. Refai M. Isolation and identification of fungi. Faculty of Veterinary Medicine. Cairo University. 1987.

16. Leslie JF, and Summerell BA. The Fusarium Laboratory Manual. Blackwell Pub. 2006; 12-13.

17. Mohammadi R, Mirhendi H, Matehkolaei AR, Ghahr M, Shidfar MR, Jalalizand N, and Makimura K. Molecular identification and distribution profile of Candida species isolated from Iranian patients. Medical Mycology 2013; (51): 657-63.

18. El-Magd M A, Abbas H E, El-kattawy A M, Mokhbatly A. Novel polymorphisms of the IGF1R gene and their association with average daily gain in Egyptian buffalo (Bubalus bubalis), Domestic animal endocrinology 2013; 45(2): 105--0.

19. Navarrete P, and Tovar-Ramírez D. Use of yeasts as probiotics in fish aquaculture. In: M.P. HernandezVergara \& C.I. Perez-Rostro (eds.). Agricultural and biological sciences-sustainable aquaculture techniques 2014; 135-72.
20. Tartor Y, Taha M, Mahboub H, El Ghamery M. Yeast species associated with diseased fish: Occurrence, identification, experimental challenges and antifungal susceptibility testing. Aquaculture 2018; 488: 134-44.

21. Refai MK, Laila A. Mohamed, Amany M. Kenawy and Shimaa El-S M.A. The assessment of mycotic settlement of freshwater fishes. Journal of American Science 2010; 6(11): 595-602.

22. Maysoon SA, Jenan MK, and Shaimaa NY. Isolation and identification of systemic mycological isolates from fishes samples that obtained from local markets in Baghdad, Iraq. World Journal of Experimental Bioscience 2016; 4(2): 143 -6.

23. Medeiros AO, Kohler LM, Hamdan JS, Missagia BS, Barbosa FAR, and Rosa CA. Diversity and antifungal susceptibility of yeasts from tropical freshwater environments in Southeastern Brazil. Water Research 2008; 42(14): 3921-9.

24. Wildgoose WH, Basva manual of ormamental fish, (Text Book), 2nd. Edition, 1992.

25. Hassan AA, Hammad AM, El Barawy AM, and Manal AH. Incidence of aflatoxigenic fungi in frozen and canned fishes and trials to inhibit aflatoxin production by use of some minor elements and lupinustermis seeds. Egypt. Journal of Applied Sciences 2007; 22(10B) 351-60.

26. Nagahama, T. Yeast biodiversity in freshwater, marine and deep-sea environments. In: Rosa, C.A., Ga'bor, P. (Eds.), Biodiversity and Ecophysiology of Yeasts. Springer, Berlin 2006; 241-62.

27. Ecker DJ, Sampath R, Li H, Massire C, and Matthews HE. New technology for rapid molecular diagnosis of bloodstream infections Expert Review of Molecular Diagnostics 2010; 10(4): 399-415.

28. Leaw SN, Chang HC, Sun HF, Barton R, Bouchara JP, and Chang TC. Identification of medically important yeast species by sequence analysis of the internal transcribed spacer regions. Journal of Clinical Microbiology 2006; 44(3): 693-9.

29. Chen YC, Eisner JD, Kattar MM, Rassoulian-Barrett SL, Lafe K, Bui U, Limaye AP, Cookson BT. Polymorphic internal transcribed spacer region 1 DNA sequences identify medically important yeasts. Journal of Clinical Microbiology 2011; 39(11): 4042-51.

30. Mousavi SA, Khalesi E, Shahidi Bonjar GH, Aghighi S, Shaifi F, Aram F. Rapid molecular diagnosis for Candida species using PCR-RFLP. Biotechnology 2007; 6(4): 583-7.

31. Ping YG, Wang L, Lu GX, Shen YN, and Lui WD. A simple and reliable PCR-restriction fragment length polymorphism assay to identify Candida albicans and its closely related Candida 
dubliniensis. Brazilian Journal of Microbiology 2012; 43(3): 873-9.

32. Gatesoupe FJ. Live yeasts in the gut: natural occurrence, dietary introduction, and their effects on fish health and development. Aquaculture. 2007;
33. Suzuki K. Fatal Trichosporon fungemia in patients with hematologic malignancies. European Journal of Haematology 2010; 84: 441-7. 267: 20-30. 